\title{
Cognitive Behavioral Therapy for Decreasing Anxiety in an Elderly Female Patient Undergoing Hemodialysis: A Single-case Study
}

\author{
C.S. Indah Gunarti ${ }^{a}$ and Lifina Dewi Pohan ${ }^{b *}$ \\ ${ }^{a}$ Clinical Adult Magister-Profession, Faculty of Psychology, Universitas Indonesia, Depok, \\ Indonesia, ${ }^{b}$ Clinical Psychology Department, Faculty of Psychology, Universitas Indonesia, \\ Depok, Indonesia
}

*Corresponding email:

Lifina Dewi Pohan

Clinical Psychology Department

Faculty of Psychology, Universitas Indonesia

J1. Lkr. Kampus Raya, Depok, Jawa Barat

Indonesia, 16424

Tel.: +62 217270004

E-mail address: lifina.dewi@ui.ac.id 


\title{
Cognitive Behavioral Therapy for Decreasing Anxiety in an Elderly Female Patient Undergoing Hemodialysis: A Single-case Study
}

\begin{abstract}
Personal loss, financial problems, decreasing responsibilities, and chronic disease increase the anxiety levels of individuals as they mature and reach late adulthood. Kidney failure is a chronic disease that is common among the elderly. Its treatment requires the long-term adaptation and lifestyle changes of the patient. Thus, patients with kidney failure often perceive that their disease will influence their future. This perception generates anxiety, which decreases the patient's quality of life, consequently affecting treatment efficacy and worsening the patient's physical condition. Given that high levels of anxiety influence the patient's mental health and disturb medical treatment, the appropriate and timely handling of the patient's medical and psychological issues is necessary. Cognitive behavioral therapy (CBT) is an intervention that aims to change the patient's perception of their disease. It aims to improve the patient's physical strength and social skills, as well as promote healthy behaviors by providing disease-related psycho-education and strategies for cognitive restructuring, relaxation, and lifestyle management. The potential of CBT as a treatment for several mental illnesses, particularly depression and anxiety, has been investigated. This study aimed to identify the effects of CBT in a patient with kidney failure. The intervention consisted of nine 30-60 min sessions. The result of qualitative assessment through observation and interview indicated that the patient's anxiety symptoms reduced in intensity. The patient began to control her anxiety and able to perform activities independently. She also reengaged in her preferred activities and stopped focusing on her disease and limitations. This study suggested that intervention with CBT may decrease the intensity of anxiety symptoms.
\end{abstract}

Keywords: anxiety, cognitive behavioral therapy, hemodialysis, kidney failure

\section{Introduction}

Over the past 60 years, cognitive behavioral therapy (CBT) has been concomitantly provided with medical approaches for the treatment of mental illness (Ehde, Dillworth, \& Turner, 2014). Beck began using CBT as intervention for depression and anxiety. Patients with anxiety have to assess the risk associated with situations that they fear, to consider their internal and external resources, and to improve their resources. CBT allows patients to address their avoidance behaviors and to confront fearful situations, thus allowing them to behaviorally test their negative predictions (Beck, 2011). Excessive anxiety that causes distress or that interferes with daily activities is an abnormal part of aging. Anxiety can worsen an elderly individual's physical health, reduce their ability to perform daily activities, and decrease their feelings of well-being (Palazzolo, 2015).

Among the elderly, anxiety emerges as a result of health, family, financial issues, and personal losses (Gauthier, 2005). Anxiety symptoms appear when an individual feels that their physical and mental capacities have decreased and when they begin to lose their independence or experience chronic disease (Gauthier, 2005). Anxiety may be linked to several important risk factors, such as perceived poor health, disability, cognitive impairment or dementia, medication side effects, and chronic illness, such as kidney failure (Pallazio, 2015). 
Chronic kidney disease can cause permanent kidney damage and requires specific treatment. Main treatment approaches for chronic kidney disease include dialysis or hemodialysis and kidney transplantation (Stein \& Wild, 2002). These treatments cannot heal kidneys but can improve the patient's health and prolong survival. Nevertheless, the treatment of patients with chronic kidney disease may encounter psychological obstacles. Stain and Wild (2002) stated that anxiety is a general problem experienced by patients with chronic kidney diseases. Anxiety symptoms include labored breathing, chest pain, sweating, and fear of dying. The appearance of these symptoms is unprompted and unpredictable. Furthermore, numerous events can result in anxiety. Dialysis and medical complications are associated with stress and anxiety, and patients with chronic kidney disease tend to experience insomnia and diminished quality of life (Gyamlani, et. al., 2011). Patients with chronic kidney disease experience anxiety because of their reduced role in family life and in the workplace, deteriorating physical skills and cognitive ability, pathological stress caused by regular hospital visits, sexual dysfunction, disease symptoms, and fear of undergoing dialysis. Lee Kim and Kim (2013) have shown that anxiety is associated with the physical health of patients with chronic kidney disease. The decrease in quality of life caused by anxiety can affect the effectiveness of the treatment and tends to worsen the patient's condition. Patients have stated that poor interpersonal relationships and quality of life, work stress, and the disease itself can cause anxiety.

The patient's behavior and interpersonal relationships can be affected by their disturbed psychological health (Stein \& Wild, 2002). The development of chronic disease is associated with decreased physical ability. In addition, chronic kidney disease can create negative thinking and emotions, such as frustration and depression. These factors can cause the patient to neglect their family and friends. These effects can further develop into stress and increase pain (Murphy, et.al., 2014).

These risk factors complicate the provision of long-term therapy, such as CBT, to the elderly. Landy et al. (2015) showed that intervention with CBT tends to improve the quality of life of older adults with chronic disease. CBT aims to improve physical health, social skill, and pain management, as well as promote healthy behaviors (Dahl \& Lundgren, 2013; Ehde, Dillworth \& Turner, 2014), by helping the patient develop an effective problem-solving attitude (Turk, Swanson \& Tunks, 2008). CBT provides disease-specific psycho-education and strategies for social skill and lifestyle management, cognitive restructuring, and relaxation. CBT is provided to patients with kidney failure to improve the efficacy of medical treatment. It focuses on understanding the meaning of personal losses and transition and accommodating cognitive decline (Palazzolo, 2015). This article will report on provision of CBT to an elderly patient with kidney failure.

\section{Methods}

\section{Participant}

This study recruited patients undergoing hemodialysis for the treatment of chronic kidney disease. The patients must meet the following criteria: presenting anxiety symptoms, such as unprompted and unpredicted panic attacks, and denying or withdrawing from hemodialysis treatment. One participant met the above criteria. The patient is an elderly woman who is 
experiencing loss because her children have left home. She has experienced anxiety because of her condition and disease and remains in the process of adaptation. She has continued to deny or withdraw from disease treatment. The life history and main disease-related problems of the participant were determined through semi-structured interviews.

\section{Research Design}

This research aimed to examine the effectiveness of CBT in a patient with kidney disease under a clinical setting. The changes exhibited by the participant before, during, and after CBT intervention were monitored and were qualitatively evaluated by examining the patterns of activities and thoughts that the participant experienced throughout the nine interventional sessions, which were conducted over a period of 2 months.

\section{Context}

The intervention was conducted at a hospital where the patient was undergoing hemodialysis and at the patient's place of residence.

\section{Approvals}

The patient provided her verbal approval for early assessment after the medical team explained the aim of the study. After assessment, the patient provided signed informed consent to receive CBT intervention concomitant with medical treatment.

\section{Measures and Materials}

The researcher did not use any psychological measurement tools. Measurements were collected on the basis of observation and interview only.

Intervention sessions were prepared on the basis of the CBT module compiled by Murphy et.al. (2015). This module was specifically designed for patients with chronic diseases of veterans and comprises twelve sessions. It was selected for this study because it corresponds with the participant's conditions of chronic disease and limited physical activity. This module can also be used to account for factors associated with aging. Changes were made to the original module in accordance with the needs and condition of the participant.

\section{Interventions}

The intervention was conducted over nine sessions and began with a pre-session that consisted of four components: (1) assessment, (2) cognitive strategy, (3) relaxation technique, and (4) physical activity encouragement. Each session lasted for 30-60 min on the basis of the participant's condition.

\section{Assessment}

On-duty doctors performed the early assessment (pre-session) of participant. The doctors reported that her psychological and physical conditions have failed to improve. The nurse in charge confirmed this report. Assessment was conducted again after the participant had undergone hemodialysis. Assessment was conducted as follows:

1. Observation

Observation was conducted during each session to monitor the changes and behavioral pattern exhibited by the patient. Observation was performed throughout the course of 
hemodialysis and focused on the relationship of the patient with health workers and other patients, the expressions of the patient while she recounted her experiences to the researcher, the course of hemodialysis, and the behavior of the patient during hemodialysis.

Patients usually fall asleep during hemodialysis. The participant, however, would stay awake and appear uneasy during hemodialysis. In one session, she looked tired and closed her eyes throughout the process. Thus, the session was not executed, and the researchers were able only to make observations related to participant conditions.

2. Interview

To collect background information about the participant's problems and personal life, the interview was conducted with counseling, active listening, and guided discovery techniques. Topics discussed during the beginning of the session were adjusted in accordance with the patient's interests. After the third session, the participant was more open, and the interview focused more on the family problems that she had experienced during her childhood. Data collection was adjusted in accordance with the participant's condition.

\section{Cognitive Strategy}

In this component, the CBT model was associated with the participant's chronic disease to help her develop cognitive problem-solving abilities. The fifth session focused on understanding the dynamics between mind and pain and recognizing the cognitive distortions that encourage negative thoughts. These strategies will help the patient understand how negative thoughts is related to pain. The researcher wrote all of the participant's thoughts in the thought record form, which contains experience (A), automatic thought (B), consequence (C), dispute (D), and effect (E). The form then verbally discussed with the participant. When discussing a negative automatic thought, the participant was asked to directly mention her thoughts upon feeling anxiety. Then, the researcher and participant discussed the effects of the thought. The researcher constructed the form to account for the participant's condition. The form was used to help the participant challenge her negative thoughts.

During the fifth session, the researcher helped the participant to actively challenge her negative thoughts with realistic and effective thoughts and problem-solving plans. This session focused on the participant's negative thoughts that cause unhealthy behavior. To challenge the participant's negative thoughts and to help her identify the effects of her thoughts and reactions, the participant was given the choice of how she thinks and reacts to an experience. Afterward, the researcher and participant discussed positive thoughts that can make negative thoughts disappear and the relationship between her mentality, behavior, and health. Positive thoughts include experiences that support mental health.

This session was performed verbally and slowly considering the participant's physical limitations. Beginning with the fifth session, the intervention was performed at the participant's home. The home visits also helped the researcher see the physical conditions of the participant's environment, her interaction with her eldest child and neighbors, and her daily activities and their effects on her condition.

\section{Relaxation technique}

Deep breathing was provided as a relaxation technique given based on the participant's physical limitations and the presence of a hemodialysis implant in her hands. 
First, the therapist explained the goals and benefits that can be obtained from deep breathing. After the participant felt motivated to learn this technique, the researcher instructed the participant to sit by leaning back in the chair and finding the most comfortable position. She was asked to take a breath, hold her breath, and slowly exhale while closing her eyes. In addition to regulating the breath, the researcher asked the participant to listen to the sounds that she heard while breathing slowly. This intervention aims to change the focus of the participant's thoughts from negative to neutral objects. The participant was asked to listen to the sounds around her because her environment was quiet and peaceful. The researcher asked the participant to practice relaxation techniques when she felt anxious, when the disease symptoms intensified, and when she was unable to sleep. However, the researcher did not evaluate how often the participant practiced the relaxation technique by herself.

\section{Termination}

The last phase of the intervention is termination, which included a review of the strategies that the participant had learned and performed during the intervention. These strategies include identifying negative thoughts, transforming negative thoughts into positive thoughts, reducing anxiety and tension, becoming an active patient, increasing her independence, resuming her daily activities, and improving her communication with her surroundings and family, especially with her son who lives away from her. The participant indicated that she understood the influence of negative thoughts on her behavior and health. Thus, she was able to begin transforming her negative thoughts into positive thoughts. The researcher also provided the participant with a relapse-prevention strategy during this phase. The provided strategy was emotion-focused strategy, which is a continuation of problem-focused strategies. The participant was encouraged to perform a relaxation technique to calm herself. When needed, she will communicate her feelings to her son.

Table 1.

Description and target of each session

\begin{tabular}{|c|c|c|}
\hline Session & Agenda & Target \\
\hline \multirow[t]{2}{*}{ Session 1} & $\begin{array}{l}\text { Collecting information on problems } \\
\text { related with the disease. }\end{array}$ & Participant describes the problems related to her perception of her disease. \\
\hline & Counseling of the problem & $\begin{array}{l}\text { Participant feels comfortable after describing her problems and build the trust with the } \\
\text { therapist.. }\end{array}$ \\
\hline \multirow[t]{2}{*}{ Session 2} & $\begin{array}{l}\text { Guided discovery of changes induced } \\
\text { by the disease. }\end{array}$ & $\begin{array}{l}\text { Participant understands how her disease affects her quality of life and mental health. } \\
\text { Then participant can identify her cognition. }\end{array}$ \\
\hline & $\begin{array}{l}\text { Psycho-education related with kidney } \\
\text { failure and anxiety. }\end{array}$ & Participant understands her disease and anxiety as an effect of the disease. \\
\hline \multirow[t]{2}{*}{ Session 3} & $\begin{array}{l}\text { Guided discovery of other problems } \\
\text { associated with the disease. }\end{array}$ & $\begin{array}{l}\text { Participant understands how other problems predispose her to disease and gain insight } \\
\text { to accept her problems. }\end{array}$ \\
\hline & Deep breath relaxation. & Participant is more comfortable after previous activities. \\
\hline Session 4 & $\begin{array}{l}\text { Introduction of ABCDE technique, } \\
\text { based on the participant's experience. }\end{array}$ & $\begin{array}{l}\text { Participant can differentiate between her thoughts and feelings. } \\
\text { Participant can identify negative thoughts related to kidney failure and hemodialysis. }\end{array}$ \\
\hline Session 5 & $\begin{array}{l}\text { Monitoring and challenging of } \\
\text { negative thoughts. }\end{array}$ & $\begin{array}{l}\text { Participant can focus on effective thoughts and decrease the frequency of negative } \\
\text { thought regarding her disease. }\end{array}$ \\
\hline \multirow[t]{2}{*}{ Session 6} & Review of session 5 . & $\begin{array}{l}\text { Participant can describe the effect of the cognitive strategy taught in previous sessions } \\
\text { on her experiences. }\end{array}$ \\
\hline & Training on relaxation technique. & Participant feels relaxed and can use the relaxation technique when she feels anxious. \\
\hline \multirow[t]{2}{*}{ Session 7} & Emphasizing the positive. & Participant can identify and focus on her positive strengths \\
\hline & $\begin{array}{l}\text { Identifying and planning pleasurable } \\
\text { activity. }\end{array}$ & $\begin{array}{l}\text { Participant plans a realistic and pleasurable activity to perform over the short and long } \\
\text { term. }\end{array}$ \\
\hline Session 8 & $\begin{array}{l}\text { Guided discovery with family } \\
\text { member. }\end{array}$ & $\begin{array}{l}\text { The participant's family can understand their cognition blocks the effective behavior } \\
\text { of the participant. The family can cooperate with the doctor to plan an effective } \\
\text { activity and treatment for the participant. }\end{array}$ \\
\hline \multirow[t]{2}{*}{ Session 9} & Monitoring of progress. & Participant can control her negative thoughts and reduce her anxiety symptoms. \\
\hline & Termination. & Participant understands that the intervention has ended and provides her feedback. \\
\hline
\end{tabular}




\section{Data Analysis}

Data were analyzed by comparing the behavioral changes shown by the participant before, during, and after intervention.

\section{Results}

Before the intervention, the participant could not clearly identify her thoughts. Guided discovery and cognitive strategy helped the participant identify and recognize her negative thoughts when experiencing anxiety about her disease.

As she recalled her past, the participant stated that she tried her best to ensure that her children found work and began families of their own. Nevertheless, she felt worthless. She felt that she only caused trouble for others and blamed herself for her disease. She was frustrated and angry because she held no hope for her future. Moreover, she could not enjoy her usual activities because she was in pain. Remembering her pain made her unhappy and tearful. Her pain influenced her sleep, and she refused to take care of herself because she felt unattractive. In the end, she felt indecisive.

The participant began to show behavioral changes during the intervention. She reported that at the beginning, she would panic when she experienced some symptoms, such as dizziness or difficult breathing. During and after the intervention, she started to control her panic. She attempted to address her anxiety by using the relaxation technique and felt that her condition improved. This progress may be attributed to counseling, which provided insight on her behavior. Furthermore, CBT strategies improved her problem-solving skills and helped her cope with her disease.

At the beginning of the intervention, the participant stopped performing her daily activities because of her disease and physical limitations. Before her illness, she owned a shop and would actively procure items for her shop. She also made her own ice for sale. These activities kept her busy and happy. In addition, she generated additional income for her personal needs and did not have to always depend on her children. After undergoing hemodialysis, her children restricted her daily activities, making her feel hopelessness. Following the intervention, which included counseling her children, communication among the participant and her sons improved. She began to communicate with her children about the activities that she enjoyed and would like to continue. The participant will resume selling, albeit at a decreased level of activity, to provide distraction from her pain.

Before undergoing intervention, the participant was a passive patient. She did not convey her disease-related concerns to her doctors and nurses despite her numerous questions about her disease. Cognitive strategy promotes the creation of positive thoughts and assertiveness. After the intervention, the participant began to take active measures against her disease. She began to communicate her perceived symptoms to the doctor. She also began to convey her desire to perform recreational activities and directly asked her doctor about appropriate outdoor activities.

Before the intervention, the participant experienced insomnia. At night, she could not sleep and would ruminate about her past. She could not fall asleep during hemodialysis because she was 
distracted by numerous thoughts that made her feel exhausted. She had stopped hemodialysis because of her declining conditions. Relaxation techniques control her thought and improved her ability to sleep.

\section{Discussion}

This section will provide discussion of the positive results of this study, the factors that might have complicated this intervention, the implications of this case for clinical intervention, potential areas for future studies, and recommendations for therapists. In general, the results of the present study showed that intensive CBT intervention effectively helped the participant understand the effects of her negative thoughts on her behavior and physical condition. It also helped her develop new effective thoughts and strategies for reducing the intensity of her anxiety.

Assessment and interviews were conducted using counseling and active listening techniques. Counseling techniques were employed to help build rapport and because the patient felt burdened with responsibilities. The presence of therapist during hemodialysis soothed the participant and made her comfortable enough to discuss her family's problems during her childhood. The well-established rapport between the participant and researcher facilitated the intervention and the participant's behavioral change. This result according to Taylor et al. (2014) that show that patients with kidney failure need a support system while undergoing hemodialysis.

The administration and procedure for CBT were adjusted in accordance with the participant's condition because physical symptoms will affect the mind. Thus, the participant must be relaxed to reduce her perceived anxiety. If the participant's anxiety level was too high, the intervention would have been ineffective. In addition, the effectiveness of the intervention was also influenced by good familial support. The participant's children understood the provided psychoeducation, and their discussions were productive.

The participant's lack of insight into her problem hindered the intervention and prolonged the counseling sessions. Cognitive restructuring was limited by the participant's age-related needs and limitations. Nevertheless, in the end, the intervention successfully helped the participant make positive changes. One limitation of this study is the unavailability of research instruments. Thus, this is not quantitative study. The location where the intervention was conducted must also be considered. Initial sessions were prolonged because they were conducted at the hospital while participant was undergoing hemodialysis. These sessions were not effective for gathering necessary information, and the patient's condition was not conducive for cognitive restructuring and behavioral modification.

Some important CBT techniques were not be implemented in this study given the participant's condition. Those techniques include homework and identifying and confronting dysfunctional core beliefs. In addition, the intervention for cognitive restructuring was conducted verbally but would have been more effective if conducted in written form. This factor may cause the patient to relapse in the future. 
The researcher only applied deep breath relaxation technique in therapy given that the participant has a medical implant that prevents her from tensing her muscles.

Regardless of the above barriers, this study indicated that CBT decreases anxiety and should be given with pharmacological therapy to a patient with chronic kidney disease and undergoing hemodialysis. This result is in line with the research conducted by Turk et al. (2008). This case study also implies that psychological techniques have to be adapted to the physical, cognitive, and emotional conditions of elderly patients with chronic diseases (Gauthier, 2005).

This study showed that simple treatments can be provided over a relatively short duration to promote healthy lifestyles among patients with chronic kidney disease. Considering that the clinic provides collaborative medical and psychological approaches as treatment to chronic disease, simple interventions of this kind should be frequently provided and implemented systematically and quantitatively. In addition, the results of this intervention indicated that CBT can be implemented to promote healthy behaviors, disease acceptance, and medication adherence, as well as alleviate insomnia. This case study can also be replicated on a large scale by using a standardized instrument and enrolling a comparison group to ensure that the causal relationship and contributions provided by the intervention can be clearly identified.

\section{References}

American Psychiatric Association. (2000). Diagnostic and Statistical Manual of Mental Disorders (4th ed.), Text Revision. Washington DC, American Psychiatric Association.

Beck, J.S. (2011). Cognitive Behavior Therapy: Basics and Beyond, $2^{\text {nd }}$ edition. New York, NY: The Guilford Press.

Chilcot, J., Wellsted, D., \& Farrington, K. (2010). Depression in end-stage renal disease: Current advances and research. Seminars in Dialysis, 2(1), 74-82.

Connell, C. (2010). Cognitive behavior therapy in the treatment of anxiety disorders in children. Rivier Academic Journal, 6(2), 1-6.

Feist, J., Feist, G. J., Roberts, \& Tomi-Ann. (2013). Theories of Personality (8 ${ }^{\text {th }}$ ed.). New York, NY: McGraw-Hill International Edition

Gauthier, J. (2005). Anxiety Disorders in the Elderly. Canada: Laval University.

Gyamlani, G., Basu, A., Geraci, S., Lee, F., Moxey, M., Clark, M., \& Dubbert, M, (2011). Depression, screening and quality of life in chronic kidney disease. The American Journal of the Medical Sciences, 342(3), 186-191.

Landy, Lauren N., Schneider, Rebecca L., Arch, \& Joanna J. (2015). Acceptance and commitment therapy for the treatment of anxiety disorders: a concise review. Current Opinion in Psychology. 2, 1-5

Lee, Y., Kim, M. S., \& Kim, S. R. (2013). Association of depression and anxiety with reduced quality of life in patients with predialysis chronic kidney disease. The International Journal of Clinical Practice. 67, 363-368.

Murphym J. L., McKellar, J. D., Raffa, S. D., Clark, M. E., Kerns, R. D., \& Karlin, B. E. (2014). Cognitive behavioral therapy for chronic pain among veterans, therapist manual. United States: Department of Veteran Affairs.

Palazzolo, J. (2015). Cognitive-behavioral therapy for depression and anxiety in the elderly. Annals of Depression and Anxiety 2(6): 1063.

Sousa, A. De. (2008). Psychiatric issues in renal failure and dialysis. Indian Journal of Nephrology. 18, 47-50.

Stein, A. \& Wild, J. (2002). Kidney Failure Explained second edition. London: Class Publishing.

Taylor, F. \& Combes, G. (2014). Supporting the emotional and psychological needs in end-stage renal disease patients. Collaborations for Leadership in Applied Health Research and Care West Midlands. United Kingdom: University of Birmingham.

Turk, D. C., Swanson, K. S. \& Tunks, E. R. (2008). Psychological approaches in the treatment of chronic pain patients; when pills, scalpels, and needles are not enough. Can J Psychiatry. 53(4), 213-223. 